\title{
FIELD CASE STUDIES OF SOIL ORGANIC MATTER SEQUESTRATION IN LITHUANIA AND THE UK
}

\author{
C.A. BOOTH ${ }^{1}$, M.A. FULLEN ${ }^{2}$, B. JANKAUSKAS ${ }^{3}$, G. JANKAUSKIENE ${ }^{3}$ \& A. SLEPETIENE ${ }^{4}$ \\ ${ }^{1}$ School of Engineering and Built Environment, The University of Wolverhampton, UK. \\ ${ }^{2}$ School of Applied Sciences, The University of Wolverhampton, UK. \\ ${ }^{3}$ Kaltinenai Research Station, Lithuanian Institute of Agriculture, Lithuania. \\ ${ }^{4}$ Chemical Research Laboratory, Lithuanian Institute of Agriculture, Lithuania.
}

\section{ABSTRACT}

Investigations have assessed the environmental benefits of soil organic matter (SOM) storage at two long-term European experimental research sites: (i) SOM data from a soil conservation (set-aside) site in the UK and (ii) SOM data from a carbon sequestration benchmarking site in Lithuania. The first case study (Hilton, UK) illustrates the environmental benefits of changes in SOM content before and after the adoption of set-aside, a recognized soil conservation technique. Ten run-off plots $\left(7-15^{\circ}\right.$ gradients) were put to ley in 1991. Run-off and erosion rates decreased to tolerable levels once $\sim 30 \%$ vegetation cover had established and remained low (mean of 69 plot years $0.21 \mathrm{t} \mathrm{ha}^{-1}$ year $^{-1}$, SD 0.14 ). Meanwhile, SOM content increased consistently and significantly on the set-aside plots (mean of $2.22 \%$ by weight in 14 years) and soil erodibility significantly decreased. Results suggest using grass-leys for set-aside is a viable soil conservation technique, which may also contribute to carbon sequestration. The second case study (Kaltinenai, Lithuania) addresses the issue of comparing international SOM databases to assist carbon modelling and carbon sequestration estimates. Five analytical approaches have been used to calculate SOM. Linear correlation and paired regression equations were used to calculate the various techniques. Correlation coefficients varied between $r=0.83-0.98(n=92, P<0.001)$. Based on the strength and significance of these relationships, it is proposed that simple linear or more complex paired regression equations can be confidently employed to recalculate SOM data between various analytical methodologies. However, it also demonstrates the potential difficulty of international carbon benchmarking, as part of the global policy to ameliorate climate change.

Keywords: carbon sequestration, land management, run-off plots, soil conservation, soil organic carbon, soil organic matter.

\section{INTRODUCTION}

Soil organic matter (SOM) content influences many soil properties, including water retention, extractable bases, capacity to supply macro- and micro-nutrients, soil aggregate stability and soil aeration [1]. SOM is increasingly recognized as an indicator of soil quality, that is, a component of biosphere sustainability and stability [2]. Soil organic fraction accounts for $50-90 \%$ of the cation exchange capacity of mineral surface soils, which allows macronutrient cations $(\mathrm{K}, \mathrm{Ca}, \mathrm{Mg})$ to be held in forms available to plants. SOM also provides much of the soil $\mathrm{pH}$ buffering capacity [3]. Nitrogen, phosphorus, sulphur and micronutrients are stored as constituents of SOM, which are slowly released by mineralization, thus aiding plant growth. Humic acids are constituents of SOM and these accelerate soil mineral decomposition, releasing macro- and micro-nutrients as exchangeable cations.

Soil organic carbon (SOC), the major component of SOM, consists of micro-organism cells, plants and animal residues at various stages of decomposition, stable 'humus' synthesized from residues and nearly inert and highly carbonized compounds, such as charcoal, graphite and coal [1]. Carbon is a major food source for soil fauna. Increasing SOM, especially SOC, changes the biological properties of soils. Therefore, increased SOC generally increases soil fauna and thus improves biodiversity. SOM increases soil porosity, thus increasing infiltration rates, which increases the water-holding capacity of soil and makes tillage operations easier. The resultant increased water availability for plants decreases both run-off and the pollution of water courses with agrochemicals. 
Impacts of SOM enrichment on soil carbon dynamics are well documented [4-6]. Conversion of natural vegetation to agricultural land-uses can decrease SOM and, conversely, conversion of cultivated land back to natural vegetation can replenish SOM [7-9] and return lost soil carbon via increased soil carbon storage [3]. Therefore, increased grass production will increase SOC and SOM and, thus, help ameliorate global warming by sequestering carbon from atmospheric $\mathrm{CO}_{2}$ into the soil store $[10,11]$.

A particular concern in many European areas is the general decline in SOM. According to the European Soil Bureau, based on the limited data available, nearly $75 \%$ of the total area analysed in the Mediterranean region of Southern Europe have low $(\leq 3.4 \%)$ or very low $(\leq 1.7 \%)$ SOM contents. Typically, agronomists consider soils with $<1.7 \%$ organic matter to be in a pre-desertification stage. The problem is widespread. For instance, SOM values for England and Wales show that the percentage of soils with $<3.6 \%$ organic matter rose from $35 \%$ to $42 \%$ in the period $1980-1995$, which is chiefly due to changing management practises. For the same period, in the Beauce region, south of Paris, SOM decreased by half, which is attributed to the same causes [12]. Because SOM decline is a crosscutting issue that also affects associated soil parameters, such as fertility, erosion and conservation, plus carbon sequestration estimates, it is extremely difficult to approximate its true environmental and financial cost [13]. With these concerns and issues in mind, this work presents SOM data from two European long-term experimental research sites: (i) SOM data from a soil conservation site in the UK and (ii) SOM data from a carbon sequestration benchmarking site in Lithuania.

\section{STRATEGIES FOR SOIL CONSERVATION}

The extent and severity of erosion on European soils has markedly increased over the last 50 years, particularly on arable land. Unfortunately, soil conservation in Europe has not generally received sufficient attention, until recently [13]. Set-aside is a scheme designed to provide farmers with a subsidy to leave land uncultivated and, in doing so, act as a possible soil conservation measure [8, 14]. In the prevailing economic climate, it is feasible that steep to moderate slopes with erodible soils, and other vulnerable parts of fields (i.e. depressions, minor dry valleys and land adjacent to water courses), be put into non-rotational set-aside [15, 16]. This could decrease erosion rates and potentially increase SOM content, with concomitant decreases in soil erodibility.

In the UK, agri-environment schemes aim at securing environmental benefits above those of Good Farming Practise and cross-compliance. Introduced in 1987, to implement EU Council Regulation $797 / 85$, they were designed to prevent loss of habitat and landscape features associated with intensification at sites targeted by the Environmentally Sensitive Areas Scheme. Subsequently, in 1991, the Countryside Steward Scheme was established to provide incentives to landowners, farmers and other land managers to take specific measures to conserve, enhance and/or re-create important landscape types. In 1994, the Habitat Scheme was initiated to create, protect and enhance wildlife habitats by removing land from agricultural production and promoting environmentally sound land-management practises. In 1995, the Moorland Scheme was launched with the objective of protecting and improving the upland moorland environment. In 1998, the Arable Stewardship Pilot Scheme was created to assess alternative arable management options for conserving and enhancing farmland biodiversity [17]. In December 2003, the UK government initiated a new agri-environment initiative, known as the Environmental Stewardship Scheme, which encourages farmers to deliver simple, yet effective, environmental management of their land [18].

\section{STRATEGIES FOR SEQUESTERING CARBON TO THE SOIL STORE}

Global $\mathrm{CO}_{2}$ concentrations are increasing and it is useful to examine these changes in terms of carbon 'sources', 'sinks' and 'pools' [19-21]. The rate of global $\mathrm{CO}_{2}$ emissions increased from $1.64 \mathrm{Gt}$ 
of carbon per year (1 Gigaton or Gt $=10^{9} \mathrm{t}$ ) to $8.05 \mathrm{Gt} \mathrm{C}$ per year between 1950 and 2000. The sources relate mainly to fossil fuel combustion, cement manufacturing, land use change and deforestation. It is estimated that the total amount of carbon in the soil 'pool' is 2300 Gt C (1550 Gt organic $\mathrm{C}$ and $750 \mathrm{Gt}$ inorganic $\mathrm{C}$ ). Both of these are much greater than the pools in either the atmosphere $(770 \mathrm{Gt} \mathrm{C})$ or in all living organisms $(610 \mathrm{Gt} \mathrm{C})$. The current $\mathrm{CO}_{2}$ 'sink' in terrestrial ecosystems (vegetation and soils) is $\sim 2.0 \mathrm{Gt} \mathrm{C}$ per year, while the oceanic sink absorbs $\sim 2.7 \mathrm{Gt} \mathrm{C}$ per year. Therefore, if carbon can be taken from the atmosphere, a small increase in the soil organic pool (0.1-0.2\% per year) could counteract the current increase in $\mathrm{CO}_{2}$ content of the atmosphere ( 1.5 parts per million by volume per year) [19-22].

Considerable organic carbon can be sequestered into soils, as carbon is an integral part of SOM. SOC constitutes $\sim 55-60 \%$, typically $\sim 58 \%$, of SOM. The potential to sequester atmospheric carbon within the soil store is a growing paradigm in soil science. The consensus is that carbon sequestration is not a panacea to global warming, but sequestration would form a valuable contribution and allow extra time while solutions to the problems are sought.

\section{SOIL CARBON MODELLING}

Carbon cycle models provide a valuable tool for understanding and predicting SOC turnover and thus assist national and international carbon sequestration estimates. To improve soil carbon modelling performance and reliability, and to demonstrate the rate and success of set-aside, it is paramount that all governments and agencies obtain national and regional SOM data to act as a benchmark for future studies. Thus, they should direct their policy to monitor the status of their national soils and to achieve proper soil use and conservation [13]. Models require the input of characteristic soil and climate data, such as soil texture, SOM, rainfall, temperature and evapotranspiration [23, 24]. Therefore, transferable soil data, beyond those of institutional and national boundaries, has international importance for soil carbon model inclusion and quantification of the global carbon budget. Unfortunately, to date, differences between international protocols employed to determine SOM content produce different estimates and interpretations.

Universal or harmonized quantification of SOM concentrations is essential and data comparability could be achieved by harmonization of analytical protocols. At present, due to methodological differences between regional and national laboratories, problems of SOM data comparison and acceptance exist, particularly where results are presented for international publication or inclusion in soil carbon models. Consequently, there is a need to develop transfer functions between analytical protocols used to determine SOM content.

\section{CASE STUDIES FOR SOIL CONSERVATION AND CARBON SEQUESTRATION}

This work presents results of two case studies: (i) SOM data from a long-term soil conservation site in the UK and (ii) SOM data from a carbon sequestration benchmarking site in Lithuania [25].

\subsection{Soil conservation: the Hilton Experimental Site, UK}

Soil conservation investigations, including the set-aside approach, are being conducted at the Hilton Experimental Site, Shropshire, UK (52.0 $\left.033^{\prime} 5.7^{\prime \prime} \mathrm{N}, 2.0^{\circ} 19^{\prime} 18.3^{\prime \prime} \mathrm{W}\right)$ (Fig. 1). The site covers 0.52 ha with an upper elevation of $67.46 \mathrm{~m}$ and slopes to the south and west. The region experiences a temperate climate with a mean annual precipitation of $620.0 \mathrm{~mm}(\mathrm{SD}=104.9, n=15$ years $)$.

An array of ten $25 \mathrm{~m}^{2}(10 \times 2.5 \mathrm{~m})$ plots (Plate 1$)$ was constructed (1981-1982) on the slope beneath the Hilton meteorological station, varying from moderately sloping $\left(7^{\circ}, 12 \%\right)$ to moderately steeply sloping $\left(15^{\circ}, 27 \%\right)$. A trough at the downslope end of each plot guided run-off and sediment 


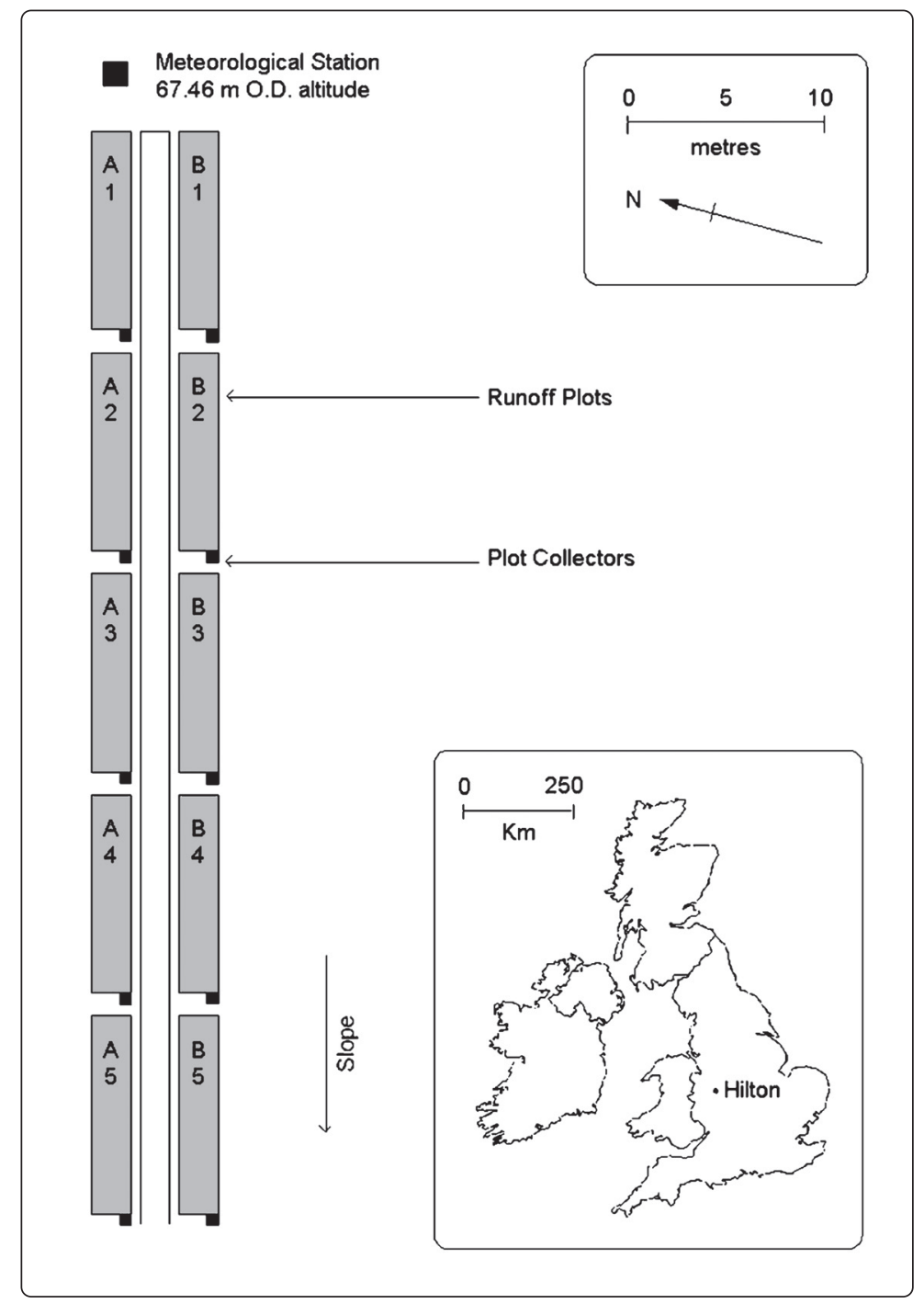

Figure 1: Plan of the field plots at the Hilton Experimental Site, UK.

into buckets, each positioned within overflow tanks. In all cases, run-off volumes were carefully decanted and measured on-site and eroded sediments were removed to the laboratory and oven-dried at $105^{\circ} \mathrm{C}$. After several years in a bare condition, the array of plots was put into set-aside, being sown with a temporary ley grass mixture on 22 April 1991 [8]. Seeds consisted of a mixture of perennial ryegrass (Lolium perenne) (varieties: Liprior, Condesa, Meltra, Antrim and Sabel), Timothy (Phleum pratense) and Huia White clover (Trifolium repens), spread at a standard application rate of $13 \mathrm{~kg} \mathrm{ha}^{-1}\left(\sim 80 \mathrm{~g}\right.$ per $\left.25 \mathrm{~m}^{2}\right)$, as advised by the UK Ministry of Agriculture, Fisheries and Food, now known as the Department of the Environment, Food and Rural Affairs. Subsequent set-aside management followed UK Ministry of Agriculture regulations [26]. These included two 


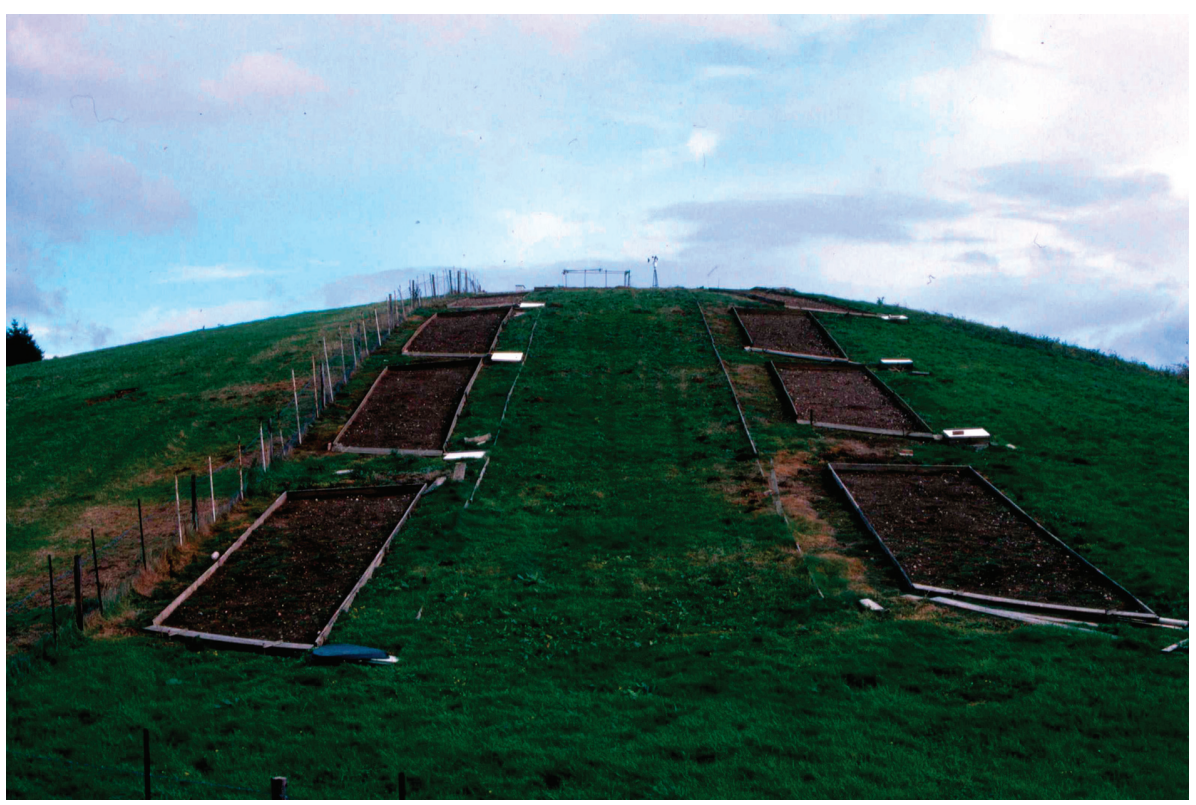

Plate 1: View of the Hilton Experimental Site run-off plots in their bare soil condition, prior to set-aside establishment (taken in 1991).

grass cuts between July and September and the grass cuttings retained on the plots. Fifty topsoil (0-5 cm deep) samples ( 60-80 g dry weight each) were removed using a hand-trowel $(\sim 10 \mathrm{~cm}$ width) from the experimental plots in December 1985, 1988, 1990 and April 1991, 1993, 1995, 1999, 2001 and 2005 ( $n=450$ samples). Five samples were removed from each plot from interrill positions at 2, 4, 6, 8 and $10 \mathrm{~m}$ on the southern side of plots on each sampling occasion. SOM contents of the fine-earth fraction $(<2 \mathrm{~mm})$ were determined by loss-on-ignition at $375^{\circ} \mathrm{C}$ for $16 \mathrm{~h} \mathrm{[27].}$

On the 10 bare soil plots, during a monitoring period of more than 5 years (1985-1991), SOM content significantly decreased (Table 1, Fig. 2). During the ley establishment period (20 May 1991 to 19 December 1991) erosion rates were moderate, with a mean plot erosion rate equivalent to $0.82 \mathrm{t} \mathrm{ha}^{-1}$. Run-off and erosion rates decreased to tolerable levels once $\sim 30 \%$ vegetation cover had established. Erosion rates on the set-aside plots with a developed ley cover continued to remain low (mean of 69 plot years $0.21 \mathrm{t} \mathrm{ha}^{-1} \mathrm{year}^{-1}, \mathrm{SD}=0.14$ ). Conversion of the 10 plots to set-aside reversed the trend of declining SOM contents, which then significantly increased, especially in the first 4 years [28]. Mean SOM content increased from 2.04\% by weight (SD 0.45, $n=50)(1991)$ to $4.26 \%$ (SD 1.06, $n=50$ ) (2005), compared with nearby permanent grassland values of $4.65 \%$ (SD 1.17, $n=20$ ).

Erosion rates were unresponsive to slope angle, suggesting leys are highly effective, even on steep slopes. Therefore, plot results confirm the logical suggestion that conversion of steep slopes with erodible soils to grass would greatly benefit soil conservation [28]. There is considerable potential for set-aside to be targeted on steep and erodible land [7, 29]. Such changes are likely to be beneficial, improving moisture retention and nutrient status and decreasing soil erodibility [30, 31]. Increased soil organic contents may also contribute to carbon sequestration [21, 32-34]. 


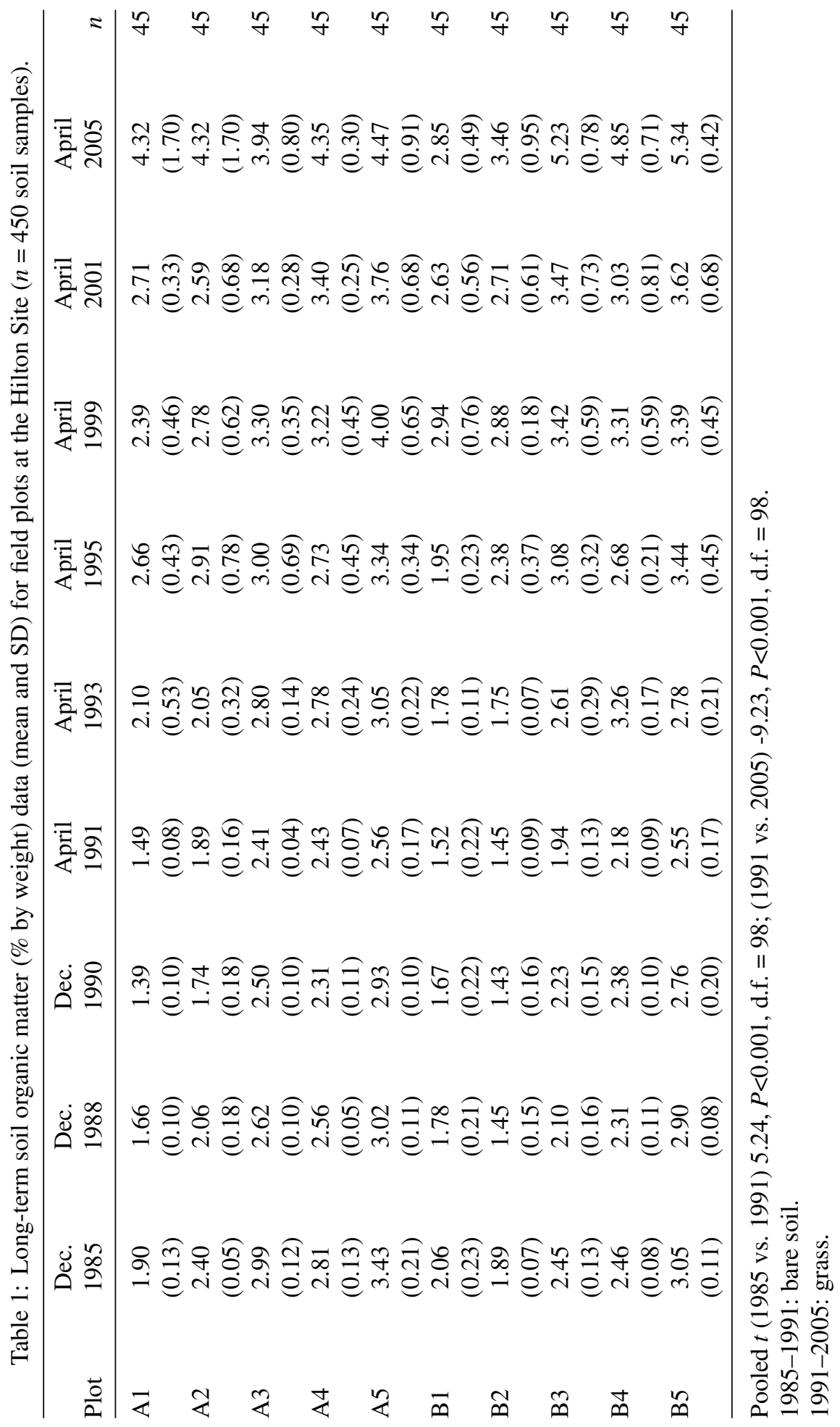




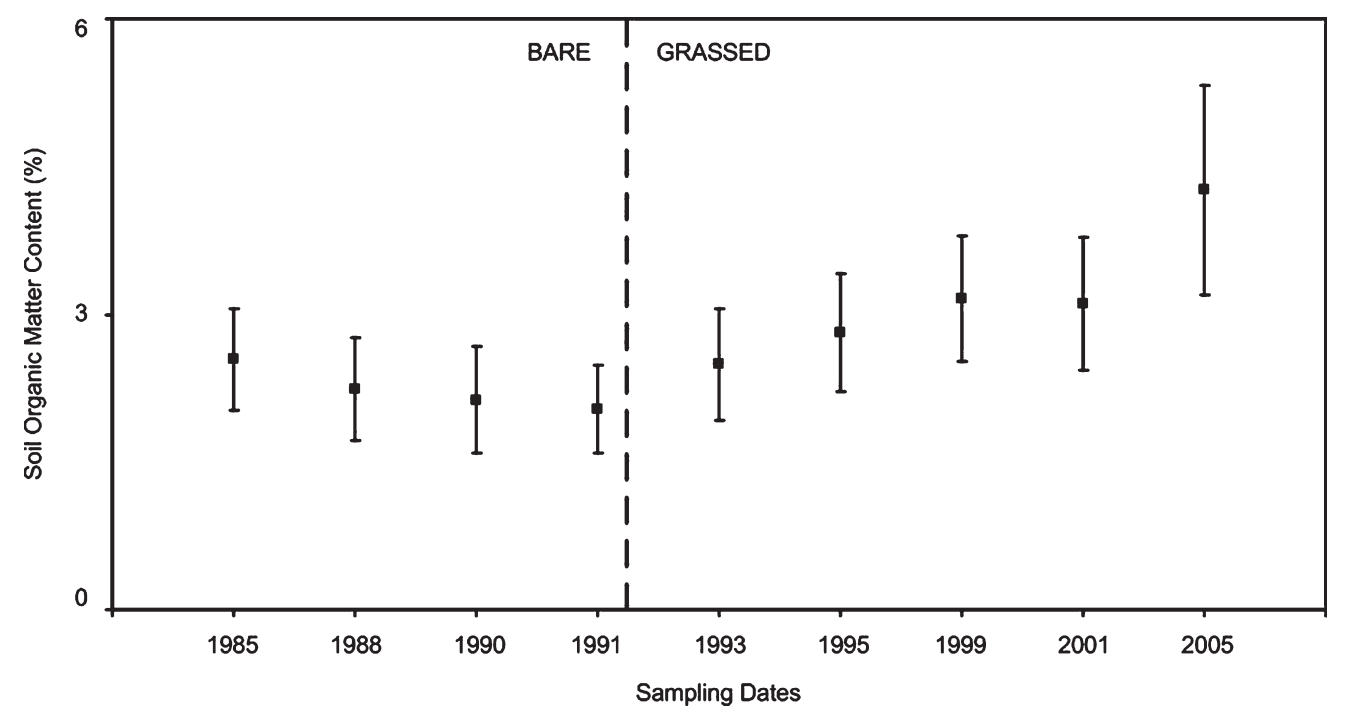

Figure 2: Temporal changes in soil organic matter (\% by weight) at the Hilton Experimental Site (1985-2005, $n=450$ soil samples).

\subsection{Soil carbon sequestration: the Kaltinenai Experimental Sites, Lithuania}

As a result of geopolitical changes, land use has changed markedly in the Baltic States (Estonia, Latvia and Lithuania). The collapse of the Soviet Union in 1991 meant the guaranteed market for arable crops produced by the Baltic States was unavailable. This promoted land use change from arable production to grassland $[35,36]$. These changes were originally perceived as negative; in hindsight, there are potential environmental benefits. For instance, the Baltic States are increasingly viewed as a regional carbon sink. This has global implications because atmospheric carbon is increasingly stored in the soil system and thus helps ameliorate global warming. Furthermore, carbon sequestration assists the Baltic States adhere to international agreements [37], such as the Kyoto Protocol and the Agenda 21 for the Baltic region (the international agreement to improve environmental conditions in the Baltic region). In the longer term, it is possible that states sequestering carbon will receive 'carbon credits;' that is, payments received from the international community to sequester carbon. Therefore, the Baltic experience provides a useful case study for environmental managers and policy makers. Specifically, negative circumstances (i.e. initial agricultural collapse) can be turned into positive developments.

Ongoing post-Soviet agricultural transformation of Lithuania, from predominantly arable to grass production, provides a timely and unique opportunity to study carbon sequestration at a period of rapid agricultural change. Thus, it is imperative to possess background information on the current status of SOM content. In doing so, this 'snapshot' provides a fixed point against which it is possible to evaluate future long-term changes. Globally, numerous field sites are 'benchmarked', collectively providing the basis for evaluations of changed soil properties [38, 39].

In 2002, as part of a joint Anglo-Lithuanian investigation into soil carbon sequestration, samples were removed from 46 experimental soil plots (Plate 2) at the Kaltinenai Experimental Sites, in the Zemaiciai Uplands of west-central Lithuania $\left(55^{\circ} 34^{\prime}, 22^{\circ} 29^{\prime}\right)$ (Fig. 3). These are permanent 


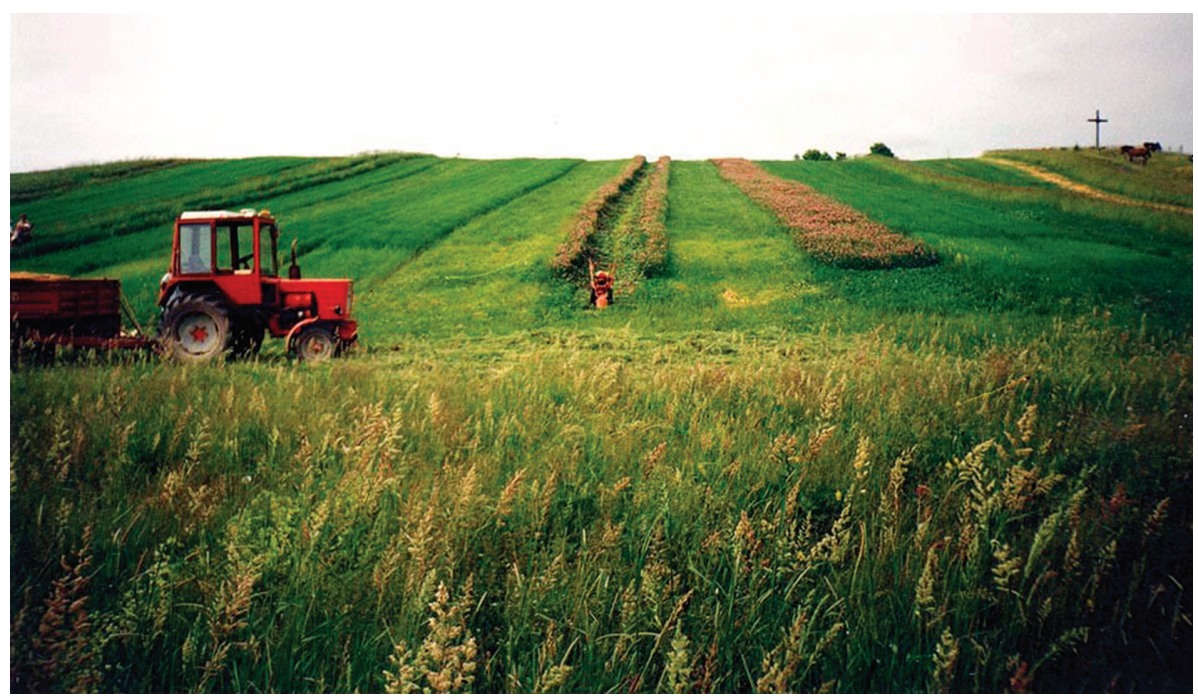

Plate 2: View of the Kaltinenai Experimental Site plots in a grassed condition (taken in 2000).

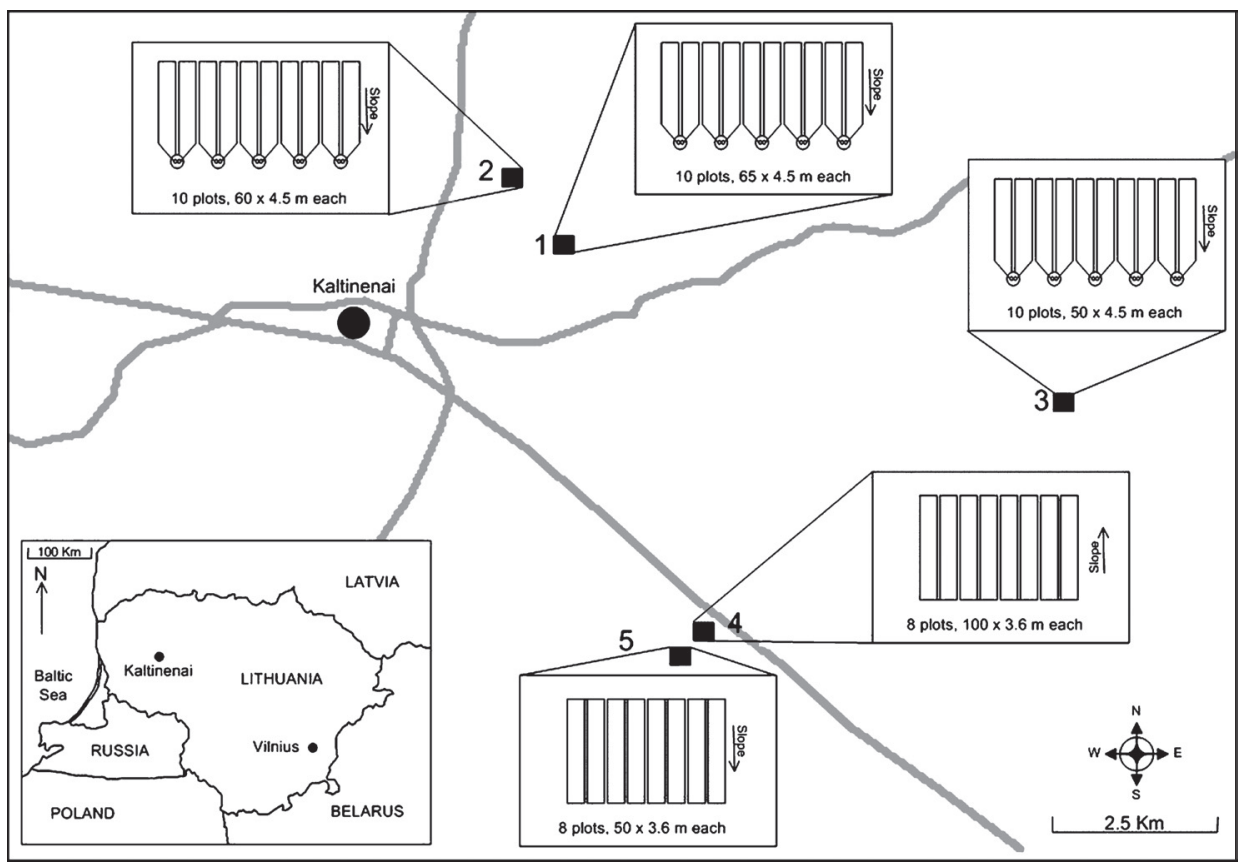

Figure 3: Plan of the field plots at the Kaltinenai Experimental Site plots, Lithuania. 
Table 2: Summary of Kaltinenai soil organic matter data ( $n=92$ soil samples).

\begin{tabular}{lcccc}
\hline Analytical technique & Mean $(\%)$ & SD & Min. (\%) & Max. (\%) \\
\hline Walkley-Black & 2.14 & 0.74 & 0.61 & 3.77 \\
Tyurin photometrical & 2.05 & 0.62 & 0.73 & 3.56 \\
Tyurin titrimetrical & 1.85 & 0.67 & 0.52 & 3.45 \\
Loss-on-ignition & 2.93 & 1.01 & 0.94 & 5.02 \\
Dry combustion & 1.94 & 0.70 & 0.43 & 3.52 \\
\hline
\end{tabular}

plots, 16 of which have been operational since 1982 and 30 since 1993 [40, 41]. Soil samples were removed, which included both topsoil (0-20 cm depth) and subsoil (20-40 cm depth), thus providing an archive of 92 soil samples. SOM content for both the topsoil and subsoil horizons was determined using five separate techniques: (i) the traditional Western Europe approach of loss-on-ignition [27], (ii) the East European Tyurin titrimetric method [42], (iii) the Tyurin photometric method [43, 44], (iv) the USDA Walkley-Black method [45] and (v) the Vario-EL III dry combustion approach [46, 47].

Table 2 shows summary SOM benchmark data [48]. Mean values (and percentage coefficient of variation) of SOM from 92 soil samples varied from $1.85 \%$ (SD $0.67, n=92$ ) analysed by the Tyurin titrimetric method and 2.93\% (SD 1.01, $n=92$ ) by loss-on-ignition (Table 2). These highlight noticeable differences between the results of each technique and stresses the difficulties in comparing international data sets. Therefore, when reporting analytical results, care must be taken to specify the precise analytical technique used. Furthermore, despite the determination of SOM being a routine procedure carried out in soil analytical laboratories throughout the U.S. and other Western countries, there is no satisfactory universal method for determining SOM content. It can be determined indirectly by measuring SOC content and multiplying the result by the ratio of organic matter to organic carbon normally present in soil. Direct determination of organic matter usually involves destruction of the organic fraction by oxidation or ignition of the soil at high temperature. Soil weight loss is taken as a measure of organic content. However, the oxidation method has serious limitations, mostly because the oxidation process is incomplete, and the extent of oxidation can vary between soils [43, 49].

At present, due to methodological differences between regional and national laboratories, problems of SOM data comparison and acceptance exist, particularly where results are presented for international publication or inclusion in soil carbon models. One way of resolving this issue is for global use of the same technique. Until such times exist, alternatively, there is a need to develop transfer functions between SOM analytical protocols using 'best fit' or regression equations, which transform data sets from one format to another.

Table 3 shows that strong correlations $(P<0.001)$ exist between all investigated methods [48], varying from $r=0.831$ [loss-on-ignition and Walkley-Black (Fig. 4a)] to $r=0.977$ [dry combustion and Tyurin photometrical (Fig. 4b)]. Therefore, these data indicate that it is feasible to transfer results generated by one method to those of other methods, using simple linear regression equations (Table 3). Although the approach may not be entirely accurate because minor data conversion errors will exist, these preliminary data provide a valuable insight for the focus of future work, which, for increased confidence, ideally should use a greater sample population and a variety of soil types. Therefore, this work also highlights that universal or harmonized quantification of SOM concentrations is essential for global carbon sequestration studies and data comparability can potentially be achieved by harmonization of analytical protocols. 
Table 3: Linear correlation and regression analyses between the various soil organic matter analytical methods ( $n=92$ soil samples).

\begin{tabular}{|c|c|c|c|}
\hline \multicolumn{2}{|c|}{ SOM methods } & \multirow{2}{*}{$\begin{array}{c}\text { Correlation } \\
\text { coefficient (linear) } \\
r\end{array}$} & \multirow{2}{*}{$\begin{array}{c}\text { Linear } \\
\text { regression equation } \\
Y=A+B X\end{array}$} \\
\hline$X$ & $Y$ & & \\
\hline Dry combustion & Loss-on-ignition & $0.870 * * *$ & $Y=0.503+1.253 X$ \\
\hline Dry combustion & Walkley-Black & $0.966 * * *$ & $Y=0.168+1.02 X$ \\
\hline Dry combustion & Tyurin photometrical & $0.977 * * *$ & $Y=0.369+0.87 X$ \\
\hline Dry combustion & Tyurin titrimetrical & $0.906^{* * *}$ & $Y=0.162+0.869 X$ \\
\hline Loss-on-ignition & Walkley-Black & $0.831 * * *$ & $Y=0.357+0.61 X$ \\
\hline Loss-on-ignition & Tyurin photometrical & $0.844 * * *$ & $Y=0.525+0.522 X$ \\
\hline Loss-on-ignition & Tyurin titrimetrical & $0.874 * * *$ & $Y=0.139+0.582 X$ \\
\hline Walkley-Black & Tyurin photometrical & $0.965 * * *$ & $Y=0.311+0.813 X$ \\
\hline Walkley-Black & Tyurin titrimetrical & $0.907 * * *$ & $Y=0.081+0.824 X$ \\
\hline Tyurin photometrical & Tyurin titrimetrical & $0.885 * * *$ & $Y=-0.112+0.954 X$ \\
\hline
\end{tabular}

$* * * P<0.001$ (critical $r$ at 90 d.f. $=0.338$ ).
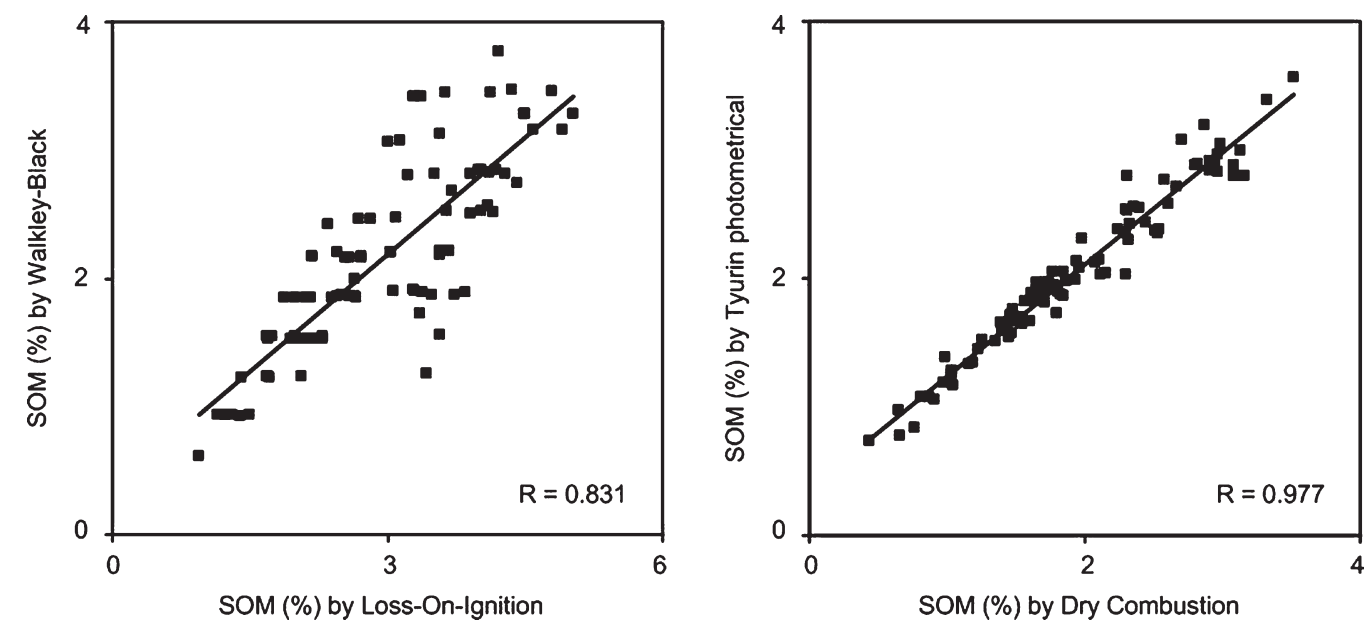

Figure 4: Bivariate scatter plots of the relationships between Kaltinenai soil organic matter data ( $n=92$ soil samples) from different analytical methods: (a) loss-on-ignition versus Walkley-Black and (b) dry combustion versus Tyurin photometrical.

\section{DISCUSSION}

These case studies illustrate important planning and policy issues. Researchers are facing multiple environmental problems and are becoming increasingly involved and responsible for global environmental management. However, this requires a holistic approach. In the case of carbon sequestration we must consider soil and climate as dynamically-interacting, mutually-adjusting systems. Thus, we need to consider the effects of our environmental management, both in terms of 
effects on the 'source' or zone of export (i.e. removing carbon from the atmospheric system) and the 'sink' or zone of import (i.e. importing carbon into the soil system). Likewise, the study also stresses the importance of scale, as the issues are relevant at global, national and local scales.

In trying to comprehend global changes, we face many challenges. These include problems of data comparability, with different countries using slightly different procedures to assess the same soil properties. Therefore, it is important that we must move towards harmonizing analytical procedures. Progress has already been made in this direction, with the Kyoto Protocol recommending standardized approaches to SOC analyses. However, harmonization in turn poses challenges. How do we compare new international databases with old national databases? Therefore, an important approach is cross-calibration of national data sets, so that important historical data can be incorporated into long-term investigations. However, cross-calibration can produce some errors. In terms of international comparisons, we face problems not only of different analytical procedures but also different definitions of the parameters. Nevertheless, rather than ignore the complexity of the problems, it is imperative we advance our knowledge and understanding to solve these problems and improve our management of our environment and its resources. As highlighted in the case study of the Baltic States, it was possible to change negative circumstances (i.e. initial post-Soviet agricultural collapse) into positive developments (increased carbon sequestration). Therefore, in the face of these and other major global challenges, we cannot afford to be too pessimistic, as it is possible to turn negative developments to our advantage.

\section{CONCLUSIONS}

Soil organic matter influences the biological, chemical and physical properties of soils and its benefits extend from local to global scales. Soil conservation and carbon sequestration are mutually important issues, coupled by the complexity of changes in SOM and the carbon cycle.

Set-aside has been shown to be a highly effective soil conservation measure, which can quickly and significantly increase soil organic content and contribute to carbon sequestration. Therefore, in accordance with long-term international strategies (e.g. the Kyoto Protocol), it is essential that land managers possess a thorough understanding of the long-term response and benefits of converting agricultural soils to grasslands and/or adopting grass ley set-aside for inclusion in future strategies and policy. Much more SOM benchmarking of international soils will make this an achievable goal and improve the harmonization of global SOM databases to enhance international estimates of soil carbon sequestration rates.

\section{ACKNOWLEDGEMENTS}

The help of colleagues, from each institution, with fieldwork is gratefully acknowledged. Some of the presented data formed part of a pilot project funded by The Leverhulme Trust Ltd (F/00630B), to whom all authors gratefully acknowledge their financial assistance. The expertise and support of academic, research and technical staff at both establishments are fully appreciated and acknowledged.

\section{REFERENCES}

[1] Nelson, D.W. \& Sommers, L.E., Total carbon, organic carbon and organic matter. Methods of Soil Analyses. Chemical and Microbiological Properties, ed. A.L. Page, ASA Monograph, No. 9, Part. 2, Madison, WI, pp. 539-579, 1982.

[2] Kogut, B.M. \& Frid, A.S., Comparison of humus determination methods in soils. Pochvovedenie, 9, pp. 119-123, 1993 (in Russian).

[3] Lal, R., Kimble, J.M., Follett, R.F. \& Stewart B.A., eds, Soil Processes and the Carbon Cycle, CRC Press: Boca Raton, FL, 1998. 
[4] Torbert, H.A., Rogers, H.H., Prior, S.A., Schlesinger, W.H. \& Runion, G.B., Effects of elevated atmospheric $\mathrm{CO}_{2}$ in agro-ecosystems on soil carbon storage. Global Change Biology, $\mathbf{3}$, pp. 513-521, 1997.

[5] van Kessel, C., Nitschelm, J., Horwath, W.R., Harris, D., Walley, F., Luscher, A. \& Hartwig, U., Carbon-13 input and turnover in a pasture soil exposed to long-term elevated atmospheric $\mathrm{CO}_{2}$. Global Change Biology, 6, pp. 123-135, 2000.

[6] Hagedorn, F., Maurer, S., Egli, P., Bucher, J.B. \& Siegwolf, R., Carbon sequestration in forest soils of soil type, atmospheric $\mathrm{CO}_{2}$ enrichment and $\mathrm{N}$ deposition. European Journal of Soil Science, 52, pp. 619-628, 2001.

[7] Fullen, M.A., Soil organic matter and erosion processes on arable loamy sand soils in the West Midlands of England. Soil Technology, 4, pp. 19-31, 1991.

[8] Fullen, M.A., Effects of grass ley set-aside on runoff, erosion and organic matter levels in sandy soils in east Shropshire, U.K. Soil \& Tillage Research, 46, pp. 41-49, 1998.

[9] Fullen, M.A., Wu, B., \& Brandsma, R.T., A comparison of the texture of grassland and eroded soils from Shropshire, U.K. Soil Tillage \& Research, 46, pp. 301-305, 1998.

[10] Stote, C., Boatman, N.D., Borralho, R.J., Rio Carvalho, C., de Snoo, G.R. \& Eden, P., Ecological impacts of arable intensification in Europe. Journal of Environmental Management, 63, pp. 337-365, 2001.

[11] Lal, R., Soil management and restoration for $\mathrm{C}$ sequestration to mitigate the accelerated greenhouse effect. Progress in Environmental Science, 1, pp. 307-326, 1999.

[12] Commission of the European Community, Towards a Thematic Strategy for Soil Protection, Communication from the Commission to the Council, the European Parliament, the Economic and Social Committee of the Regions: Brussels, 2002.

[13] Fullen, M.A., Arnalds, A., Booth, C.A., Castillo, V., Kertesz, A., Martin, P., Souchere, V., Sole, A. \& Verstraeten, G., Government and agency response to soil erosion risk in Europe. Soil Erosion in Europe, eds J. Boardman \& J. Poesen, John Wiley \& Sons Publishers: Chichester, UK, pp. 805-826, 2006.

[14] Chisci, G., Perspectives on soil protection measures in Europe. Conserving Soil Resources: European Perspectives, ed. R.J. Rickson, CAB International: Wallingford, UK, pp. 339-353, 1994.

[15] Ministry of Agriculture, Fisheries and Food, The Soil Code, MAFF Publications: London, UK, 66 pp., 1998.

[16] Environment Agency, Best Farming Practices: Profiting from a Good Environment, Environment Agency Publications: Bristol, UK, 57 pp., 2001.

[17] Ecoscope Applied Ecologists, Review of Agri-Environmental Schemes - Monitoring Information and Research and Development Results, Final report for the Department of Environment, Food and Rural Affairs: London, 2003.

[18] http://www.defra.gov.uk/erdp/reviews/agrienv/default.htm (accessed 25 June 2008).

[19] Batjes, N.H., Total carbon and nitrogen in the soils of the world. European Journal of Soil Science, 47, pp. 151-163, 1996.

[20] Lal, R., Soil carbon dynamics in cropland and rangeland. Environmental Pollution, 116, pp. 353-362, 2002.

[21] Lal, R., Soil erosion and the global carbon budget. Environmental International, 29, pp. 437450, 2003.

[22] Fullen, M.A. \& Catt, J.A., Soil Management - Problems and Solutions. Arnold Publishers: London, UK, 269 pp., 2004.

[23] King, A.W., Post, W.M. \& Wullschleger, S.D., The potential response of terrestrial carbon storage to changes in climate and atmospheric $\mathrm{CO}_{2}$. Climate Change, 35, pp. 199-227, 1997. 
[24] Smith, P., Powlson, D.S., Glendining, M.J. \& Smith, J.U., Potential for carbon sequestration in European soils: preliminary estimates for five scenarios using results from long-term experiments. Global Change Biology, 3, pp. 67-79, 1997.

[25] Booth, C.A., Fullen, M.A., Jankauskas, B., Jankauskiene, G. \& Slepetiene, A., The role of soil organic matter content in soil conservation and carbon sequestration studies: case studies from Lithuania and the U.K., Sustainable Planning \& Development II, eds A.G. Kungolos, C.A. Brebbia \& E. Beriatos, WIT Press: Southampton, pp. 463-473, 2005.

[26] Ministry of Agriculture, Fisheries and Food, Set-Aside, Advisory Leaflet PB 0299, MAFF Publications: London, UK, 23 pp., 1991.

[27] Ball, D.F., Loss-on-ignition as an estimate of organic matter and organic carbon in non-calcareous soils. Journal of Soil Science, 15, pp. 84-92, 1964.

[28] Fullen, M.A. \& Booth, C.A., Grass ley set-aside and soil organic matter dynamics on sandy soils in Shropshire, U.K. Earth Surface Processes and Landforms, 31, pp. 570-578, 2006.

[29] Guerra, A., The effect of organic matter content on soil erosion in simulated rainfall experiments in W. Sussex, U.K. Soil Use and Management, 10, pp. 60-64, 1994.

[30] Foster, I.D.L., Fullen, M.A., Brandsma, R.T. \& Chapman, A.S., Drip-screen rainfall simulators for hydro- and pedo-geomorphological research: the Coventry experience. Earth Surface Processes and Landforms, 25, pp. 691-707, 2000.

[31] Wedin, D.A. \& Tilman. D., Influence of nitrogen loading and species composition on the carbon balance of grasslands. Science, 274, pp. 1720-1723, 1996.

[32] Lal, R., Modest proposal for the year 2001: we can control greenhouse gases and feed the world with proper soil management. Journal of Soil and Water Conservation, 55, pp. 429-433, 2000.

[33] Lal, R., Soil erosion and carbon dynamics, Soil \& Tillage Research, 81, pp. 137-142, 2005.

[34] Chambers, B.J. \& Garwood, T.W.D., Monitoring of water erosion on arable farms in England \& Wales. 1990-94. Soil Use \& Management, 16, pp. 93-99, 2000.

[35] Lithuanian Statistical Office, Agriculture and Forestry - Statistical Yearbook of Lithuania 1994-1995, Vilnius, pp. 298-309, 1995 (in Lithuanian and English).

[36] Lithuanian Statistical Office, Agriculture and Forestry - Statistical Yearbook of Lithuania 2000, Vilnius, pp. 387-426, 2000 (in Lithuanian and English).

[37] Intergovernmental Panel on Climate Change (IPCC), Climate Change 2001: The Scientific Basis. Summary for Policymakers (Third Assessment Report), Geneva, Switzerland, 2001.

[38] Krogh, L., Noergaard, A., Hermansen, M., Humlekrog Greve, M., Balstroem, T. \& Breuning-Madsen, H., Preliminary estimates of contemporary soil organic carbon stocks in Denmark using multiple datasets and four scaling-up methods. Agriculture, Ecosystems \& Environment, 96, pp. 19-28, 2003.

[39] Leifeld, J., Bassin, S. \& Fuhrer, J., Carbon stocks in Swiss agricultural soils predicted by land-use, soil characteristics and altitude. Agriculture, Ecosystems \& Environment, 105, pp. 255-266, 2005.

[40] Jankauskas, B. \& Jankauskiene, G., Erosion-preventive crop rotations for landscape ecological stability in upland regions of Lithuania. Agriculture, Ecosystems \& Environment, 95, pp. 129-142, 2003.

[41] Jankauskas, B., Jankauskiene, G. \& Fullen, M.A., Erosion-preventive crop rotations and water erosion rates on undulating slopes in Lithuania. Canadian Journal of Soil Science, 84, pp. 177-186, 2004.

[42] Aleksandrova, L.N. \& Naidenova, O.A., Laboratory Practice in Soil Science. Kolos: Leningrad, 1976 (in Russian). 
[43] Orlov, D.S. \& Grisina, L.A., Guide to the Chemistry of Humus. MGU Press: Moscow, 1981 (in Russian).

[44] Nikitin, B.A., 1999. A method for soil humus determination. Agricultural Chemistry, 3, pp. 156-158, 1999.

[45] USDA, Primary characterization data. Soil Survey Laboratory Information Manual. NSSC, SSL: Lincoln, NE, pp. 9-133, 1995.

[46] Schmidt, M.W.I., Skjemstad, J.O., Gehrt, E. \& Kogel-Knabner, I., Charred organic carbon in Chernozemic soils. Eurasian Journal of Soil Science, 50, pp. 351-365, 1999.

[47] Butkute, B. \& Slepetiene, A., Near-infrared reflectance spectroscopy as a fast method for simultaneous prediction of several soil quality components. Chemija, 15, pp. 12-20, 2004.

[48] Jankauskas, B., Jankauskiene, G., Slepetiene, A., Fullen, M.A. \& Booth, C.A., International comparison of analytical protocols for determining soil organic matter content on Lithuanian Albeluvisols. Acta Universitatis Latviensis, 692, pp. 66-77, 2005.

[49] Rojkov, V., Konjushkov, D. \& Kogut, B., Distribution of the reserves of organic matter in the soil cover of Russia, 17th World Congress in Soil Science (Bangkok, Thailand), Symposium paper no. 44, Thailand, pp. 2237-1-2237-13, 2002. 